\title{
Copper nanoparticles induced, trimesic acid grafted cellulose-an effective, non-hazardous processing approach for multifunctional textile with low chemical induction
}

\author{
Nasir Sarwar • Usama Bin Humayoun • Ghulam Dastgeer • Dae Ho Yoon
}

Received: 23 March 2021 / Accepted: 1 October 2021 / Published online: 22 October 2021

(C) The Author(s), under exclusive licence to Springer Nature B.V. 2021

\begin{abstract}
Cross-linkers have great importance in textile due to the widespread utilization of cellulosic fibers for clothing. Unfortunately, the acute toxicity of formaldehyde-based resins and the poor performance of non-formaldehyde resins still keep the research door open for scientists in this area. Herein, we demonstrated copper nanoparticles induced trimesic acid grafted cellulose as a sustainable solution for multifunctional easy-care clothing. Our treated fabric presents crease recovery angle value of $248^{\circ}$ comparable to that of most promising citric acid-based cross-
\end{abstract}

Supplementary Information The online version contains supplementary material available at https://doi.org/10.1007/ s10570-021-04251-5.

N. Sarwar · D. H. Yoon

School of Advanced Materials Science and Engineering, Sungkyunkwan University, Suwon 16419, Republic of Korea

N. Sarwar · U. Bin Humayoun

Department of Textile Engineering, Lahore (Faisalabad

Campus), University of Engineering and Technology,

Lahore 38000, Pakistan

G. Dastgeer

Department of Physics and Astronomy, Sejong

University, Seoul, Republic of Korea

D. H. Yoon $(\bowtie)$

SKKU Advanced Institute of Nanotechnology (SAINT), Sungkyunkwan University, Suwon 16419, Republic of

Korea

e-mail: dhyoon@skku.edu linkers at the chemical concentration of trimesic acid as low as $2 \%$ with a sweeping improvement of around $30 \%$ in strength retention, not reported earlier. The relatively low fabric stiffness, without any yellowing, is contributing to the comfort and aesthetic demand while nanoparticles induction promoting utmost antimicrobial need. For the first time, the superiority of the development was validated by interlacing the fabric/finish traits with sustainability building blocks that provide the step forward for rapid industrialization. Furthermore, environmental, health, and safety mapping comparison provides a better understanding of the intensity of hazards that different finishing crosslinkers pose on the environment and public health. With improved performance and superior sustainability, such fabric can act as a preferable alternative to the multifunctional easy-care fabric market. 


\section{Graphic abstract}

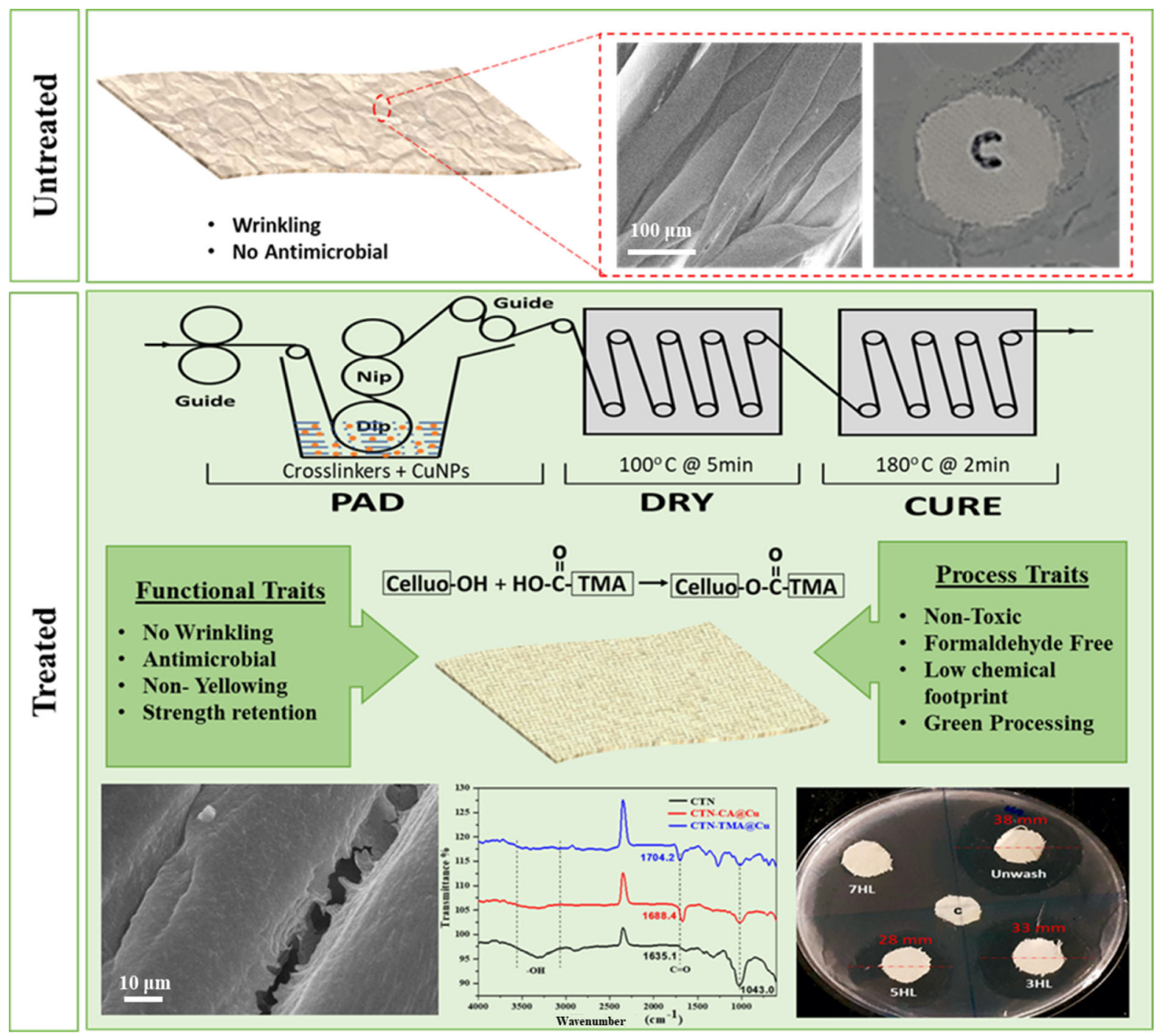

Keywords Non-hazardous cross-linkers ·

Sustainable easy-care $\cdot$ EHS mapping ·

Multifunctional textile $\cdot$ Low chemical footprint

\section{Introduction}

Multifunctional clothing is a great need of time not only for technical textiles but also for casual wear and home textile. Such clothing should fulfill not only the purpose of protection but also satisfy the aesthetic demands with ease of utilization. In the current era of the pandemic, raising awareness about personal hygiene, self-care, and environmental concerns, created a huge market of sustainable clothing with improved antimicrobial performance and hassle-free utilization with durability and comfort (Nimkar 2018). The global antimicrobial textile clothing market was estimated of worth 9.5 billion USD in 2019 and is expected to reach 12.8 billion USD by 2025 with an approximate CAGR growth rate of nearly $5.4 \%$ (Global Antimicrobial Textile Markets 2021). The clothing industry found a matchless utilization of cotton in shirts, suits, trousers, blouses, beddings, workwear, and formal wear due to its exceptional 
comfort, strength, absorbance, ease of dyeability, and biodegradability (Tausif et al. 2018). Despite numerous advantages, excessive wrinkling, poor repellence, and thermal resistance, and microbial attack are the major constraints in its widespread utilization. The severe wrinkling in cotton leads to an expensive and time taking ironing process eventually huge energy consumption (Bhaduri and Bagchi 2019) while microbial attack resulting in hygiene issue (Mohsin et al. 2016). Technological advancements in textile manufacturing have served the problem but coupled with the severe downside disadvantages and obvious stress on the environment, manufacturers, and users (Berradi et al. 2019). Synthetic fibers being inherently wrinklefree were blended with cotton to impart a smooth wrinkle-free appearance but with compromise on fabric comfort and handle (Chen et al. 2017).

Surface modification of textile materials with chemical treatment is the most versatile way to impart functional properties with ease of application. In past, different chemical compounds (phenol/formaldehyde, melamine/formaldehyde, and urea-formaldehyde) have been proposed to impart crease recovery properties to cotton clothing but these were subjected to skin irritation, acute toxicity, and carcinogenicity, due to formaldehyde contents (Van den Broek et al. 2020; Liu et al. 2016). Day by day increasing awareness about green manufacturing processes, sustainable clothing and strict complies requirements resulted in the development of modified urea-formaldehyde resins as next-generation cross-linkers with low formaldehyde release. Although initiation of modified crosslinking systems limits the formaldehyde release but lacks in required performance and effective crosslinking. Cotton due to its semi-crystalline hydrophilic nature provides an ideal surface for the growth of odor-causing microbes. Further, the infestation of microorganisms resulted in fermentation, strength loss, and discoloration of clothing (Arafa Badr 2018). Polycarboxylic acids, being able to crosslink with the hydroxyl group of the cellulose through esterification, were introduced as a new class of formaldehyde-free easy-care finish with intrinsic antimicrobial properties. Butane tetracarboxylic acid (BTCA), citric acid (CA), maleic acid (MA), and succinic acid (SA) were broadly studied in literature as a formaldehyde-free durable press finish for cellulosic (Sarwar et al. 2019). BTCA is way too costly for commercial use. Citric acid and maleic acid are linked with the severe yellowing issue and strength loss, hence ruining the aesthetic look of the clothing (Luo et al. 2020) Succinic acid was found ineffective to provide required easy-care performance (Ibrahim et al. 2018).

The significant reduction in strength is another common disadvantage associated with all types of easy-care finishes. Liang et al. (2020) employed a copolymer of acrylic acid and maleic acid on cellulose with the hope to reduce strength loss but remained unsuccessful in achieving substantial outcomes. Nanotechnology revolutionized the manufacturing of functional textiles with its cutting-edge benefits and cost-effectiveness. Metal oxide nanoparticles were used to catalyze the esterification reaction of carboxylic acids with the least effect of tensile strength, but results were not significant (Sarwar et al. 2019). Ibrahim et al. (2020) incorporate silver nanoparticles and fluorocarbon with dimethylol-dihydroxy-ethylene urea (DMDHEU) and study their impact on improved functionality considering various cellulosic fabrics and their blend. Although most of the reported literature presents noticeable improvement in easycare performance along with antimicrobial properties, overcoming the strength loss and fabric yellowing is still a challenge (Ahmed et al. 2021). On the other hand, high chemical consumption in textile processing for required easy-care performance still has some unavoidable side effects even if a used chemical is not toxic (Fig. S1) (Abdel-Salam et al. 2014).

In the current pandemic of Covid-19, where the world is reshaping itself, wearing sustainable clothing has appeared as an utmost desire of consumers with the least chemical exposure, additive hygiene, and durability (Karim et al. 2020). According to the report published by the business research company (TBRC), the market of sustainable functional textiles is expected the increase by $9.1 \%$ in 2025 with exponential growth in antimicrobial and easy-care clothing (TBRC 2020). Considering the diversifying need for sustainable and multifunctional easy-care clothing, our research group proposed trimesic acid (TMA) as a highly effective, non-toxic alternative crosslinking system for cellulosic textile. The detailed demonstration of EHS and sustainability mapping provide a step forward toward industrial adaptability. Copper once again proofs its importance for today's world with minimum disinfectant life of Corona Virus when encountering it (Suman et al. 2020). Copper 
nanoparticles, being an excellent disinfectant, were incorporated in the finishing recipe to impart antimicrobial activity. The treated fabric presents easy-care performance comparable to that of most effective citric acid at an exceptionally low concentration of $2 \%$ with excellent strength retention. The color aesthetics of the treated fabric remained ineffective without any significant change in whiteness index along with maintaining the antimicrobial performance even after successive washing cycles. With the high risk of infections in hospitals and other medical care units, such finish can also find rapid industrial adaptation with tremendous utilization in medical textile and personal hygiene products with hassle-free utilization and service life.

\section{Experimental}

\section{Materials}

$100 \%$ cotton fabric scoured and bleached, without any prior finishing, was sourced from Nagina Textiles, Pakistan. Copper nitrate, trimesic acid (TMA), and sodium dodecyl sulfate and hydrazine liquid were purchased from Sigma Aldrich, Korea while citric acid (CA) and sodium hypophosphite (SHP), tween 80 and ethanol were sourced from Dae-Jung Chemicals, Korea. All the samples were used as received without further purification.

\section{Synthesis of copper nanoparticles}

Copper nanoparticles were synthesized through the wet processing method as described in the literature with modification (Sarwar et al. 2021). Briefly, $15 \mathrm{ml}$ of $0.1 \mathrm{M}$ copper salt solution was taken in a break and heated up to $80^{\circ} \mathrm{C}$ with continuous stirring at 800 RPM. $1.6 \mathrm{~g}$ of citric acid was then added followed by stirring for $15 \mathrm{~min}$ to obtain a homogenous mixture. Citric acid was widely studied as a capping cum complexing agent which shields the nanoparticles and prevents them against oxidation. In the next step, $1.2 \mathrm{~g}$ of sodium hypophosphite was dissolved in $5 \mathrm{ml}$ of water and added dropwise in copper salt-citric acid solution while keeping the setup under constant stirring (800 RMP @ $90{ }^{\circ} \mathrm{C}$ ). With the addition of SHP, the color of the solution start changing instantly from turquoise blue, brick orange to dark brown as a result of the reduction. After aging for $1 \mathrm{~h}$, the solution was centrifuged at 8000 RPM for $15 \mathrm{~min}$, the supernatant was poured off and particles were washed three times with ethanol. After washing particles were stored in $0.01 \%$ hydrazine solution in ethanol.

\section{Preparation of TMA Finish}

To prepare the stable water-soluble finish of Trimesic acid (TMA), first, the excess of TMA was dissolved in $20 \mathrm{ml}$ of ethanol through sonication at $60{ }^{\circ} \mathrm{C}$. Water was then added to the solution to make a total volume of $100 \mathrm{ml}$ and marked as solution "A". In a separate beaker, $1 \mathrm{~g}$ of Tween-80 (a non-ionic emulsifying cum homogenizing agent) and $0.2 \mathrm{~g}$ of sodium dodecyl sulfate (as dispersant) was mixed in $10 \mathrm{ml}$ of water and marked as part "B". Solution "B" was added dropwise in solution " $A$ " in a manner that the final solution contains $5 \mathrm{gm} / \mathrm{l}$ of Tween 80 and $1 \mathrm{gm} / \mathrm{l}$ of sodium dodecyl sulfate. Finally, the mixture was sonicated for $20 \mathrm{~min}$, resulting in a clear solution without any sedimentation even after two months. The as-prepared emulsion was readily used as an easy-care finish in subsequent trials as per requirement.

Fabric preparation and finishing

As received fabric (Table S1) was thoroughly washed and neutralized before any chemical application. The $\mathrm{pH}$ of fabric was checked using standard test method number AATCC 81. The neutralized fabric was then padded in finishing solution with varying concentration of crosslinker as in Table 1 . The wet pick up was kept constant at $70 \%$ in all trials (eq-1). $100 \mu \mathrm{g} / \mathrm{ml}$ of as-synthesized copper nanoparticles was also added to each finish bath as an antimicrobial agent. The treated samples were dried at $100{ }^{\circ} \mathrm{C}$ for 5 min followed by curing at $180{ }^{\circ} \mathrm{C}$ for $2 \mathrm{~min}$. All samples were subjected to conditioning $(65 \pm 4 \%$ humidity, $20 \pm 2{ }^{\circ} \mathrm{C}$ temperature) for $24 \mathrm{~h}$ before proceeding for any test. The schematic of the development is presented in Fig. 1.

$\%$ Pickup $=\frac{\text { weight of fabric (after application) }- \text { weight of fabric (before application) }}{\text { weight of fabric (before application) }} \times 100$ 
Table 1 Design of experiment with fabric performance results*

\begin{tabular}{|c|c|c|c|c|c|c|}
\hline \multirow[t]{2}{*}{ Sample ID } & \multicolumn{2}{|c|}{ Crosslinker (\%) } & \multirow{2}{*}{$\begin{array}{l}\text { Catalyst }(\%)^{* *} \\
\text { Sod. hypophosphite }\end{array}$} & \multirow{2}{*}{$\begin{array}{l}\text { Crease recovery } \\
\text { angle }\left(^{\circ}\right) \\
(\text { warp }+ \text { weft })\end{array}$} & \multirow{2}{*}{$\begin{array}{l}\text { Tensile Strength } \\
\text { Retention }(\%)\end{array}$} & \multirow{2}{*}{$\begin{array}{l}\text { CIE whiteness } \\
\text { index }(\%)\end{array}$} \\
\hline & Citric acid & Trimesic acid & & & & \\
\hline Control & - & - & - & 123 & 100 & 73 \\
\hline $\mathrm{S} 1$ & 1.5 & - & 1.2 & 134 & 92.4 & 68.5 \\
\hline $\mathrm{S} 2$ & 3.0 & - & 2.4 & 147 & 86.2 & 62 \\
\hline $\mathrm{S} 3$ & 6.0 & - & 4.8 & 198 & 73.7 & 56 \\
\hline S4 & 9.0 & - & 7.2 & 254 & 68.3 & 53 \\
\hline S5 & - & 0.5 & 0.4 & 174 & 95.1 & 70 \\
\hline S6 & - & 1.0 & 0.8 & 204 & 91.7 & 70 \\
\hline S7 & - & 1.5 & 1.2 & 241 & 90.5 & 68 \\
\hline S8 & - & 2.0 & 1.6 & 248 & 89.4 & 68 \\
\hline S9 & - & 2.5 & 2 & 224 & 90.7 & 69 \\
\hline
\end{tabular}

*Each finishing bath (S1-S9) also contains $100 \mu \mathrm{g} / \mathrm{ml}$ of CuNPs

**0.8 molar ratio of citric acid as per typical norm (Sarwar et al. 2019)

\section{Characterizations}

\section{Analytic assessment}

The treated fabric and as-synthesized nanoparticles were characterized using various techniques. Surface morphology was observed using FE-SEM (JEOL, JSM-13-7600F) field emission scanning electron microscope. Synthesis of copper nanoparticles was confirmed through UV-Vis spectroscopy while phase identification was made through X-Ray diffraction using Bruker 14-D8-FOCUS diffractometer equipped with $\mathrm{Cu} \mathrm{K} \alpha$ radiation $(\lambda=1.5418 \AA)$ at $40 \mathrm{~mA}$ and $40 \mathrm{kV}$ at a scale range of $30-80^{\circ}$.

\section{Crease recovery angle measurement}

For evaluation of fabric easy care functionality, BSEN-22313 (1992) standard method was followed to measure crease recovery angle (CRA). Fabric sample of size $(4.0 \times 1.5) \mathrm{cm}$ was bend at centre and placed under standard load for 5 min. Recovery angle was measured after specific time using Shirley Crease Recovery Tester. Ten values were recorded in each warp and weft direction and sum of average warp and weft crease recovery angle was used.

\section{CIE whiteness index}

For the assessment of the degree of whiteness, the colorimetric coordinates of treated samples were measured using a spectrophotometer (datacolor 550). CIE whiteness index was calculated using (Eq. 2) as per the standard protocol of AATCC-110-1995.

$\mathrm{W}_{\mathrm{CIE}}=\mathrm{Y}+800\left(\mathrm{x}_{\mathrm{o}}-\mathrm{x}\right)+1700\left(\mathrm{y}_{\mathrm{o}}-\mathrm{y}\right)$

$\mathrm{Y}$ is the tristimulus value where $\mathrm{x}$ and $\mathrm{y}$ are the colorimetric coordinates of the tested sample while $\mathrm{x}_{\mathrm{o}}$ and $y_{o}$ are the coordinates of achromatic point for $10^{\circ}$ observer under D65 light source.

\section{Stiffness and bending length}

ASTM 4032 standard test method was used to measure the fabric stiffness. A $(8.0 \times 4.0)$ inch rectangular piece of fabric was folded to make a two-ply $(4.0 \times 4.0)$ inch square sample and mounted over an orifice of stiffness tester. The fabric is then push through the orifice by the plunger to a distance of $57 \mathrm{~mm}$ and maximum force (in $\mathrm{kg}$ ) to circular bending of fabric is recorded as stiffness. For bending length, free bending of fabric to $41.5^{\circ}$ angle was measured and flexural rigidity was calculated as per protocol describes in ASTM-D-1388. 


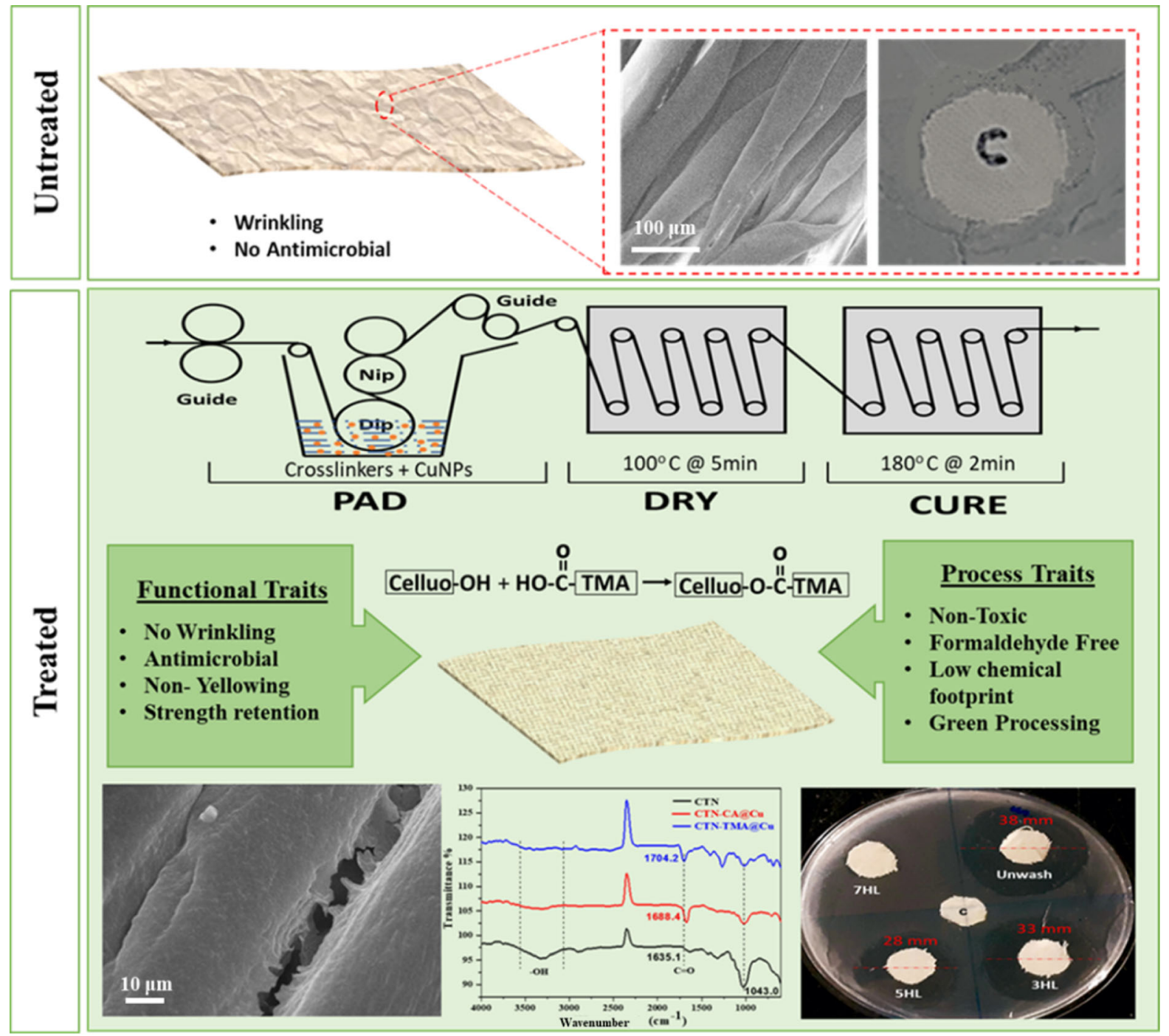

Fig. 1 Schematic of development and characteristic traits a Untreated fabric b Treated fabric

Tensile strength (TS) was evaluated using ASTMD5034 while antimicrobial performance was accessed with the standard disc diffusion method.

\section{Results and discussion}

Synthesis of CuNPs and characterization

Copper nanoparticles were synthesized through the chemical reduction method using sodium hypophosphite as a non-toxic reducing agent in presence of citric acid (as a capping cum stabilizing agent). The significantly high reduction potential of the sodium hypophosphite $\left(E^{0}=-1.57 \mathrm{~V}\right)$ made it an effective reducing agent (Polimbetova et al. 2004). In the proximity of sodium hypophosphite, the transfer of an electron from SHP to $\mathrm{Cu}^{++}$resulted in the formation of zerovalent copper nanoparticles. The reaction equation of the SHP reduction is presented in Eq. 1 (Sarwar et al. 2021). As soon as copper nuclei formed, citric acid (present in solution) radially absorbed in the surface of Cu-NPs hence provide encapsulation (Deng et al. 2013).

$\mathrm{H}_{2} \mathrm{PO}_{2}^{-}+\mathrm{Cu}^{++} \stackrel{\mathrm{H}_{2} \mathrm{O}}{\longrightarrow} \mathrm{Cu}^{\mathrm{o}}+\mathrm{H}_{3} \mathrm{PO}_{4}+4 \mathrm{H}^{+}$ 
The UV absorption spectrum is considered one of the most useful tools to study nanoparticles due to their unique peak position and shape. Copper nanoparticles were found to present a surface plasmonic effect in the range of $570-610 \mathrm{~nm}$. The as-synthesized copper nanoparticles were redispersed in ethanol after washing and subjected to UV-Vis spectroscopy. The absorption peak at $589 \mathrm{~nm}$ was attributed to the surface plasmonic peak of $\mathrm{Cu}$-NPs (Fig. 2a). To confirm the stability of the as-synthesized Cu-NPs, the aliquot of the nanoparticle solution was stored at room temperature and reanalysed thereafter. The almost similar spectrum pattern without any noticeable change even after 30 days depicts the stability of $\mathrm{Cu}-\mathrm{NPs}$. The slight redshift in the UV spectrum might be due to aggregation. For morphological view, the assynthesized nanoparticles were examined by SEM while the crystallite phase was accessed through XRD. Figure $2 b$, portrays the formation of the monodisperse round, spherical nanoparticles. The XRD spectrum of the as-synthesized nanoparticles reveals the formation of the face-centered cubic structure of copper without any impurity. The diffraction peaks at $43.5^{\circ}, 50.6^{\circ}$, and $73.4^{\circ}$ were indexed to (111), (200), and (220) planes respectively, and were in clear agreement with standard JSPDS of copper (JCPDS 04-0836) (Kumar et al. 2020) with little deviation (Fig. 2c). This deviation with a bit of background noise might be due to the surface absorption of citric acid (Yokoyama et al. 2018).
Evaluation of fabric functional performance and characterization

\section{Crease recovery angle (CRA) and physical properties}

Table 1 present the results of crease recovery angle (CRA), strength, and whiteness index of the treated samples against different concentrations of resin, crosslinked with cotton in presence of $\mathrm{NaH}_{2} \mathrm{PO}_{2}$ (as a catalyst) under the same condition. The shifting of the hydrogen bonding and plastic deformation under pressure, rubbing, and bending with the ability not to come back to its original position, resulted in wrinkle formation in cotton fabric (Ahmed et al. 2021). Crease recovery angle value is the standard method used to indicate the ability of clothing material to resist wrinkling. Fabric with a higher crease recovery angle (CRA) has a better ability to prevent wrinkling. The untreated fabric, as expected, showed a very low CRA of $123^{\circ}$ (Table 1). Both citric acid (CA) and trimesic acid (TMA) were found effective with a significant upsurge in CRA due to esterification between - $\mathrm{COOH}$ and $-\mathrm{OH}$ of crosslinkers and cotton respectively (Fig. S2; Table 1) The degree of crosslinking depends on the concentration of crosslinkers. CA crosslinked with $-\mathrm{OH}$ group of cotton by the formation of intermediate cyclic anhydride, restrict the movement of polymeric chains, hence, improved CRA (Mohsin et al. 2013). The highest CRA of $254^{\circ}$ was observed with $9 \%$ of CA (S4). Although the results were interesting but subjected to a substantial strength loss of $32 \%$ (Table 1, S4). Due to considerable strength loss, a citric acid concentration above $9 \%$ was not studied. The fabric strength and shade are the key performance indicators of fabric serviceability and (a)

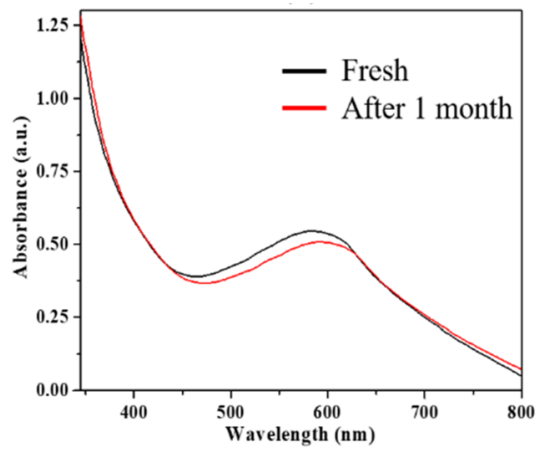

(b)

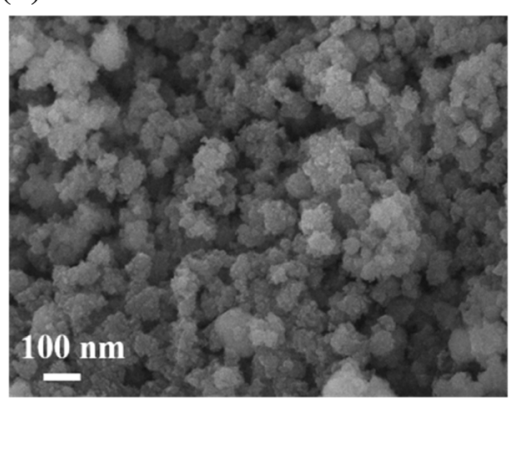

(c)

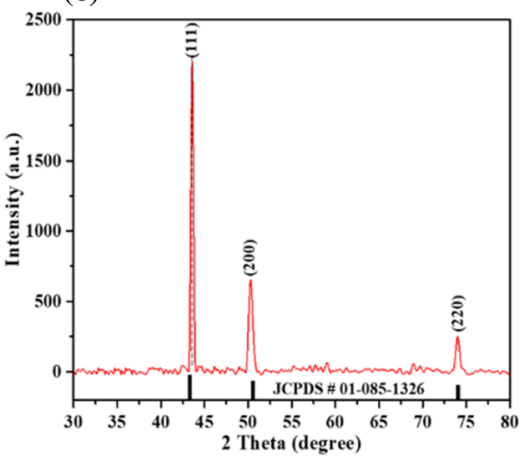

Fig. 2 Characteristics of as-synthesized copper nanoparticles a SEM b UV absorption spectrum c XRD 
aesthetic demand that cannot be compromised (Sarwar et al. 2020). The CA while curing is partially converted into aconitic acid, with strong absorption in the wavelength range of $400-550 \mathrm{~nm}$, resulting in yellowness in white fabric (Luo et al. 2020). A drastic decline in the whiteness index of the treated fabric was observed with an increasing amount of citric acid along with strength loss (Table 1). Sample S4 showed a WI value of 53 that was around $27 \%$ lower than untreated fabric (control). Fabric easy-care performance also improved linearly with TMA concentration with a maximum CRA value of $246^{\circ}$ at a concentration level of $2 \%$ only (Sample S8). TMA treated fabric (sample 8) demonstrates CRA merely comparable able to sample $4\left(\mathrm{CRA}=254^{\circ} @ 9 \% \mathrm{CA}\right)$ with such a low chemical concentration, surprisingly without adversely affecting fabric strength and color aesthetic (Table 1, Fig. S3). Aromatic carboxylic acid crosslinked the cellulosic material directly through Fischer esterification reaction, without undergoing the intermediate anhydride formation, resulted in improved wrinkle resistance without affecting color aesthetics (Qi et al. 2016; Lange and Obendorf 2015). The excessive over-coating by increasing the concentration of TMA beyond 2\% made the fabric stiffer consequently decrease in CRA (sample S9). As long as physical performance is concerned, S8 presents only $11 \%$ strength loss in comparison to untreated fabric (around 30\% better than sample S4) while maintaining the WI value of 69 as compared to the original value of 72 of control (Table 1). The slight reduction in WI might be subjected to the heating process while curing (Manasoglu et al. 2019). The strength retention in sample S8 is subjected to a high diffusion distance of TMA in cellulose. TMA due to large molecular size crosslinks uniformly on the surface (Qi et al. 2016). The TMA-TMA intermolecular hydrogen bonding is also very important in this regard (Li et al. 2020). Due to intermolecular attraction, the TMA molecules developed hen-cage webbed structure (Kolotuchin et al. 1996) and crosslinked with cellulose through esterification (Lee et al. 2003) subsequently contribute to the strength (Fig. 3) (Yan et al. 2017).

Sample S8 owing to effecting anti-wrinkling performance with the least effect of fabric strength and whiteness index was subjected to SEM analysis along with sample S4 and control. The untreated sample exhibit a clean and smooth convoluted fibers surface without any crosslinking (Fig. 4a). Both samples S4 and S8 showed crosslinking (with the respective crosslinker) that was established from FTIR analysis in the coming Sect. "Fabric stiffness and bending angle length". In contrast, to sample S4, fabric treated with trimesic acid (sample S8) presents more uniform coverage all over the fibers as depicted from surface morphology (Fig. 4b, c). To confirm the deposition of copper nanoparticles on fabric, Sample 8 was further examined by EDX along with element mapping. The appearance of a small, tiny peak at $1.00 \mathrm{keV}$ in the EDX spectrum portrays the presence of copper nanoparticles on the fabric while element mapping demonstrated the homogenous distribution of copper nanoparticles throughout the sample (Fig. 4d-h).

FTIR spectrum of the TMA and CA treated cotton fabrics (sample S4 \& S8) along with untreated cotton fabric (control) is presented in Fig. 5a. In the control sample, the broad spectrum in between 3100 and $3600 \mathrm{~cm}^{-1}$ is attributed to the -OH group of the cotton (Patil and Netravali 2020). The strong band with maxima at $1043 \mathrm{~cm}^{-1}$ is the illustrated characteristics due to overlapping of $\mathrm{C}-\mathrm{C}, \mathrm{C}-\mathrm{O}$, and $\mathrm{C}-\mathrm{O}-\mathrm{C}$ functional groups of cotton while the peak at $1635.1 \mathrm{~cm}^{-1}$ might be due to the presence of water in cotton (Doh et al. 2013). The emergence of the new peaks at $1688.4 \mathrm{~cm}^{-1}$ and $1704.2 \mathrm{~cm}^{-1}$ in the FTIR spectrum of samples S4 and S8 respectively, represents the ester linkage formed as the result of crosslinking between - $\mathrm{OH}$ group of cotton and crosslinkers (Mohsin et al. 2016). Further, smoothing of $-\mathrm{OH}$ peak is in accordance with the indication of the utilization of -OH groups in crosslinking. The FTIR spectrum of sample S8 with the variation of curing temperature was also performed. The absence of carbonyl peak in sample S8 indicates that no esterification occurs at $100{ }^{\circ} \mathrm{C}$. Sharping of the carbonyl peak at $1704.2 \mathrm{~cm}^{-1}$ along with gradually flatting $-\mathrm{OH}$ hump, in the wavelength range of $3100-3600 \mathrm{~cm}^{-1}$ present the formation of more ester linkage at elevated temperature (Fig. 5b). Considering the industrial feasibility and to avoid thermal degradation curing beyond $200{ }^{\circ} \mathrm{C}$ was not studied. The XRD spectrum of the fabrics before and after finishing is shown in Fig. 5c. The diffraction peaks in the untreated sample (control) at $14.6^{\circ}, 16.6^{\circ}$, and $22.4^{\circ}$ present the (110), (110), and (200) crystalline planes of cotton (cellulose-I) respectively, whereas, peak at $34.4^{\circ}$ is subjected to (004) plane (Schramm and Amann 2019). The roughly similar cellulose-I peaks in treated 


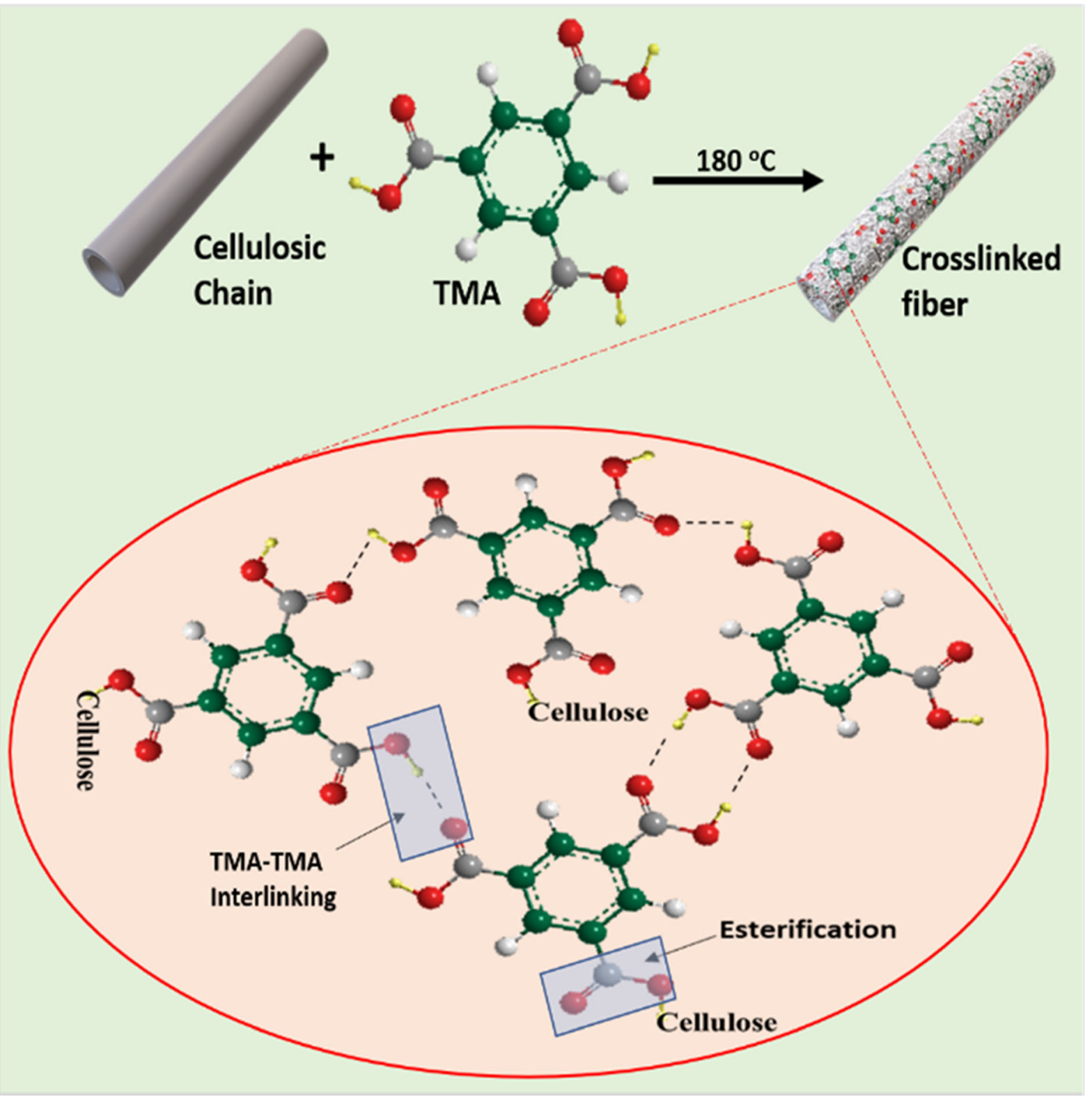

Fig. 3 Crosslinking mechanism of TMA with possible esterification

samples show that the internal crystallinity of the treated samples is not affected in the finishing process. However, peak intensity changed as a result of crosslinking (Wan et al. 2020). The slight peak shifting in treated samples might be due to crosslinking between cellulose and the finish. The appearance of new diffraction peaks (in samples S4 \& S8) at $43.3^{\circ}$, $50.8^{\circ}$, and $74.3^{\circ}$ are attributed to the presence of metallic copper nanoparticles integrated with fabric and correspond to (111), (200), and (220) planes respectively. The detection of these new peaks, in agreement with the standard JCPDS-01.085-1326 of copper, without any additional peak, indicates the presence of a face-centred cubic structure of copper nanoparticles that remain stable during the curing process (Yokoyama et al. 2018). TMA subjecting to large molecular structure, crosslinked on the surface, developed the staked structure, consequently, 


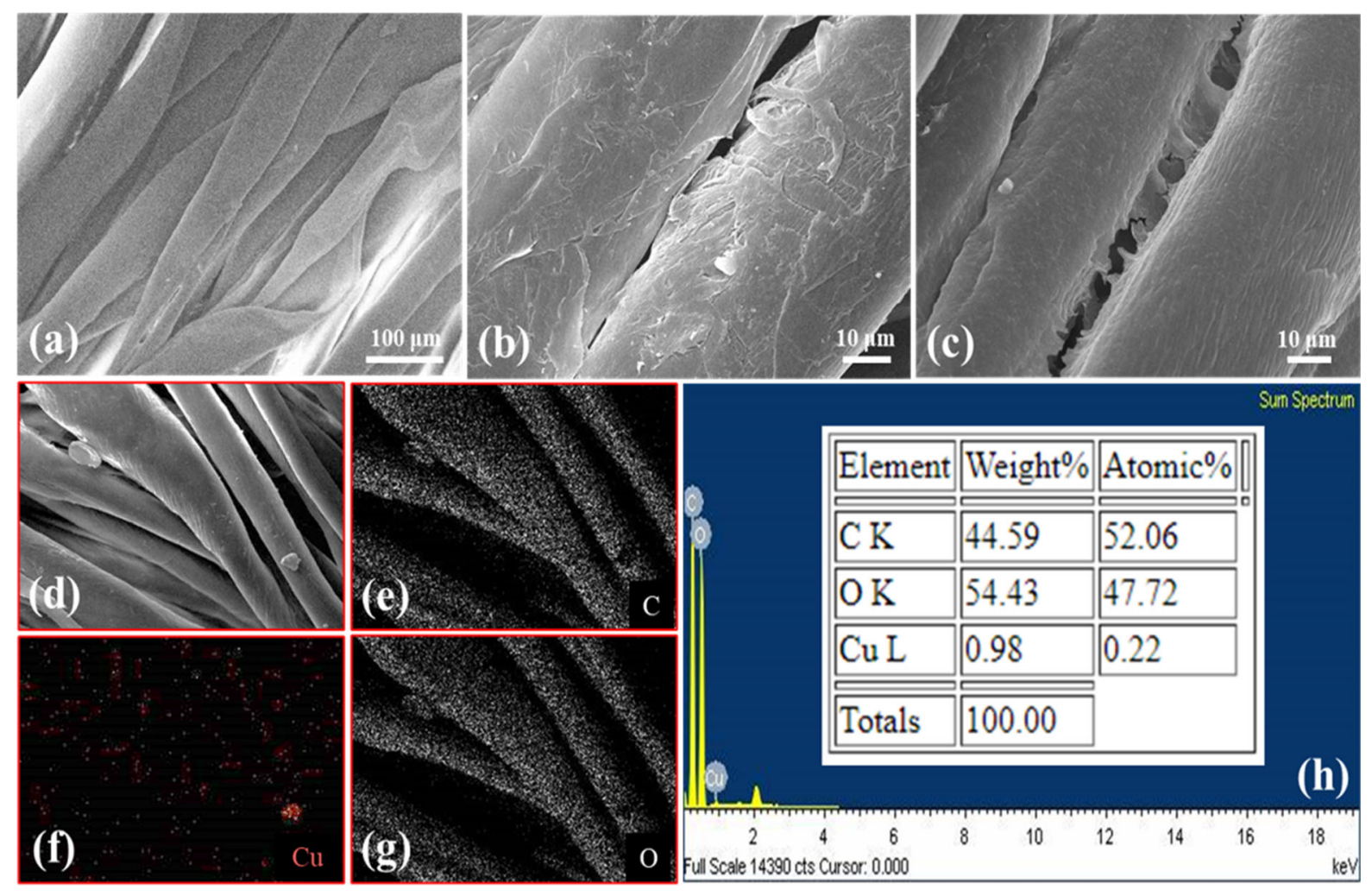

Fig. 4 SEM of treated and untreated fabric presetting crosslinking $\mathbf{a}$ untreated fabric $\mathbf{b}$ citric acid-treated $\mathbf{c}$ trimesic acid-treated (d-h) EDX element mapping with EDX Spectrum

contribute the crystallinity. The same is reflected from a slender increase in peak intensity of cellulose-I in sample 8 .

\section{Fabric stiffness and bending angle length}

Fabric handle and drape is the most important property that plays an important role in terms of sale and selection of clothing for the user. Considering the evaluation of fabric comfort and drape properties, fabric stiffness and flexural rigidity are considered as key performance indicators. Low fabric stiffness and flexural rigidity lead to better fabric handle and drape. Typically, all easy-care finishes, as a result of crosslinking, restrict the inter-fiber movement consequently adversely affects the fabric stiffness with high static and kinetic friction (Hameed et al. 2016). All treated samples showed a sweeping increase in fabric stiffness as a result of crosslinking. An increase in fabric stiffness was observed with the increasing amount of crosslinkers regardless of the type of crosslinker. Sample S4 and S8 both showed an almost similar value of fabric stiffness but sample S8 has a slightly less value of stiffness (Fig. 6a). Similarly, the flexural rigidity of sample S8 was found to be 1.2 against the 1.5 value of citric acid-treated sample (sample S4). TMA due to its large molecular size is mostly crosslinked at the surface. The relatively low inter-fiber friction in core with less crosslinking contributes to the easy movement subsequently comparatively better handle and drape (Tahvildar et al. 2019).

\section{Antimicrobial Properties}

Typically, a textile is made up of natural fibers that are easily attacked by microbes. The fibrous structure and hydrophilic nature of woven cellulosic textile provide a suitable environment for microbial growth with an odor. Considering the importance of hygiene, especially in the current pandemic era, the demand for sustainable clothing with the ability to suppress the growth of microbes and viral activity has increased drastically. Copper nanoparticles, subjected to 
(a)

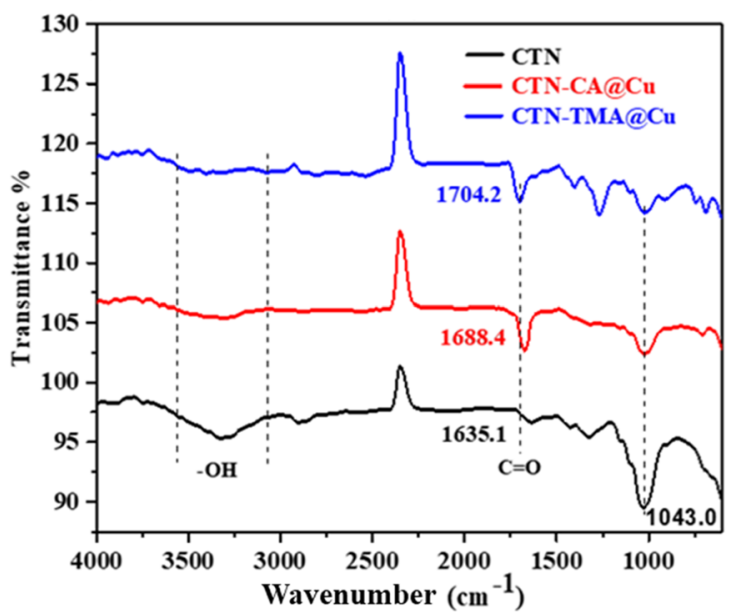

(c)

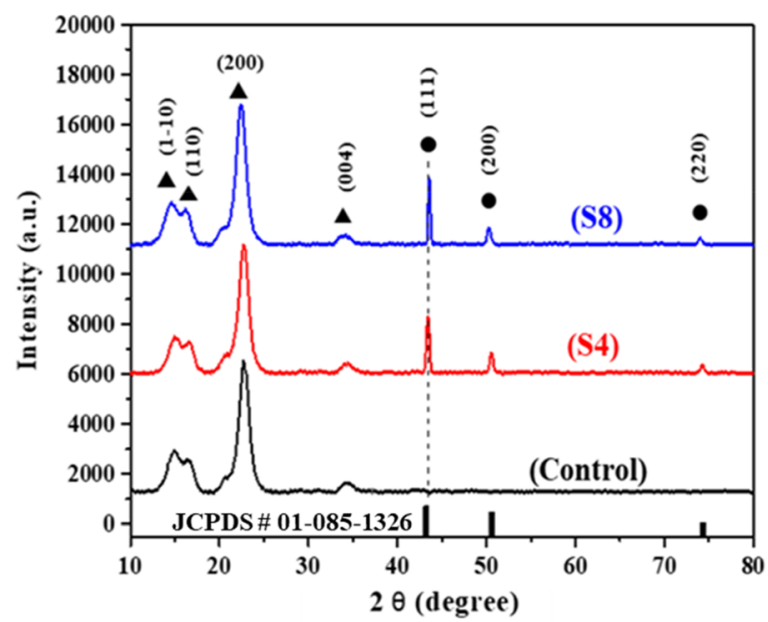

(b)

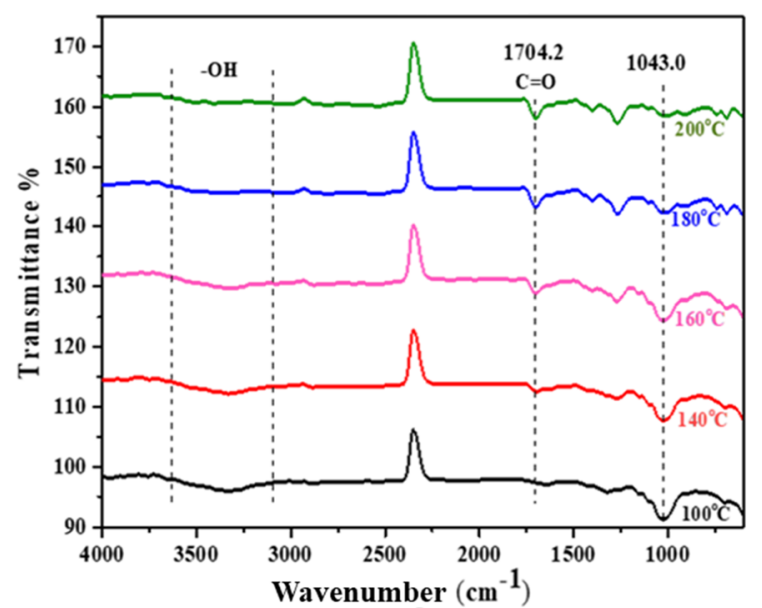

(d)

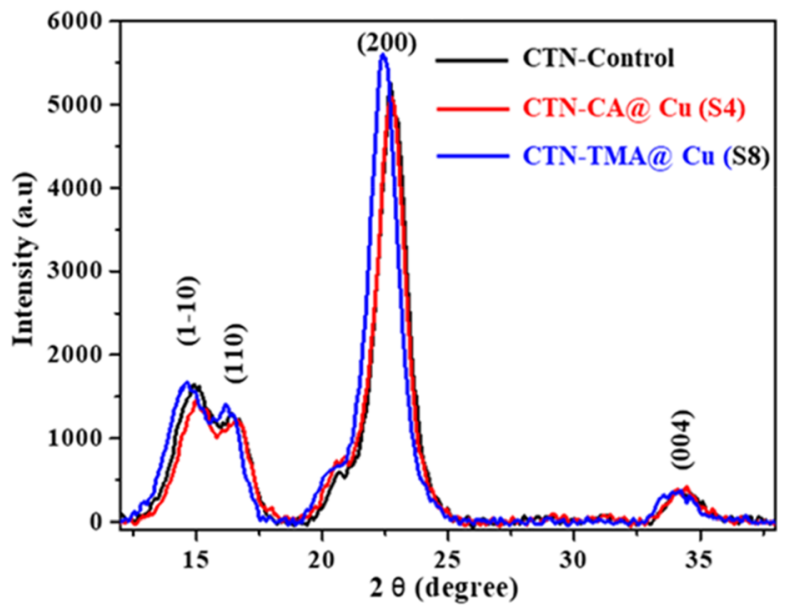

Fig. 5 Analytical characteristic of the treated fabric a FTIR Spectrum of selected samples $\mathbf{b}$ Effect of curing temperature as function of crosslinking $\mathbf{c}$ XRD spectrum of treated and untreated fabric d Magnifying view of XRD cellulosic peaks

(a)

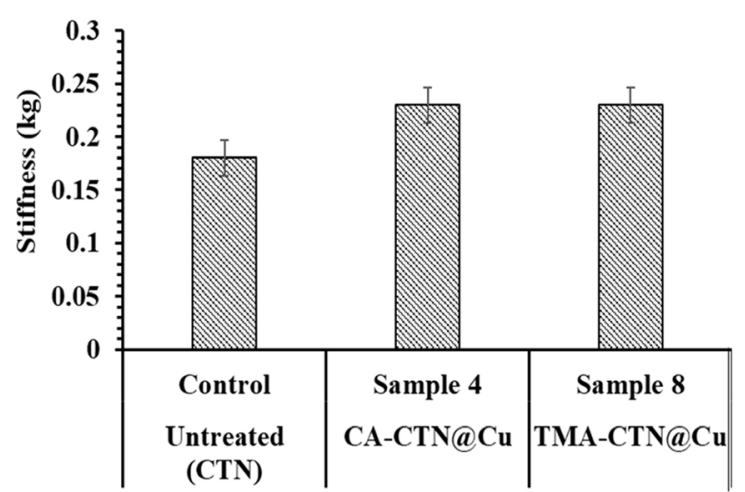

(b)

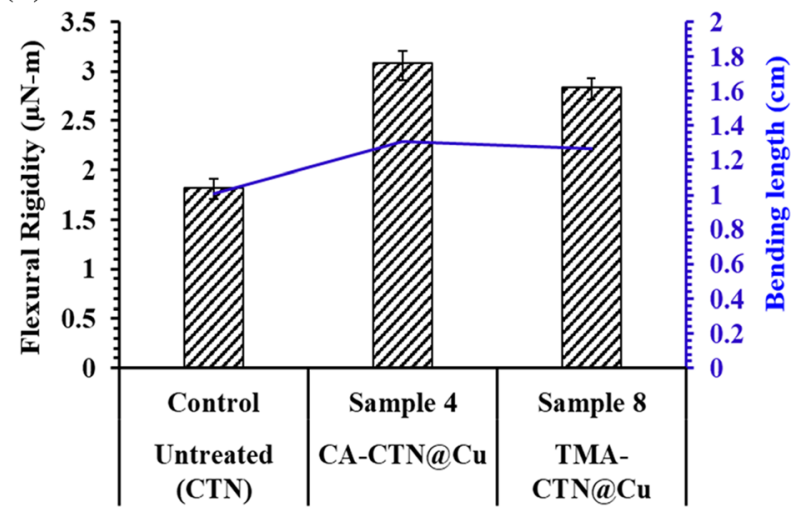

Fig. 6 Fabric comfort performance a Fabric stiffness $\mathbf{b}$ Flexural rigidity and bending length 
effective antimicrobial and covid-19 viral inhibitor (Guesmi et al. 2019), were incorporated in the finishing recipe. The antimicrobial action of the copper is very complex however, it is well agreed that on coming in contact, copper nanoparticles damage the respiratory chains and imperiled the bacterium metabolism (Woźniak-Budych et al. 2017). The treated sample S8 presents effective antimicrobial performance against both types of pathogenic strains, S. aureus (gram-positive) and E. coli (gram-negative), even after successive home laundering (Fig. 7). The gradual decrease in antimicrobe performance was observed in successive washing. It might be due to the washing-off of nanoparticles in laundering. The high antimicrobial performance in sample S8 is due to the combined action of $-\mathrm{COOH}$ group of trimesic acid and CuNPs (Fig. S4). The carboxylic groups $(\mathrm{COOH})$ promote puncturing the bacterial cell wall by lowing the $\mathrm{pH}$. The easy diffusion of copper nanoparticles through ruptured cell wall resulted in rapid dilapidation of bacterium DNA through respiration reduction eventually the cell death (Shams et al. 2020). The variation in bacterial suspension activity among both strains is referred to as the difference in cell wall thickness. S. aureus subjected to wider cell wall have relatively low suspension than E. coli (Guesmi et al. 2019).

Sustainability study of the development

For any clothing finish, to be adopted at an industrial scale as a sustainable alternative, it is necessary to evaluate it in the sustainability domain considering all three basic sustainability building blocks i.e. social and performance, environmental and economical (Lindahl 2019). The drawn integration of the fabric characteristic traits with sustainability is given in Fig. 8a. The use of non-hazardous TMA with improved fabric strength, whiteness index, antimicrobial properties with effective easy-care performance are the fabric traits directly contributing to the social and performance factor of sustainable clothing development. The improved fabric strength subjected to better service life consequently contributed to economic factors while low chemical consumption also leads to less development cost (Sarwar et al. 2020). The interlinking of each feature of the fabric with stimulating sustainability building block (indicated with coloured arrows) provides detailed insight into the development as a sustainable alternative to fabric easy-care finish (Fig. 8a). Since CTN-TMA@Cu crosslinking system is developed as a sustainable alternative to fabric durable press finishing, it is crucial to validate the finish with conventional crosslinkers based on environment, health, and safety (EHS) profile. EHS mapping depicts the superiority of the TMA in comparison with already adopted finishes (Fig. 8b). Conventional formaldehyde-based durable press finishes present a worse EHS profile due to toxic formaldehyde content (Liu et al. 2016). TMA presents the most favorable EHS profile with the lowest overall health hazardous rating of " 2 " while OSHA 29 CFR 1910.1200 hazardous nature statement symbols also state TMA as least toxic in comparison of CA, BTCA,
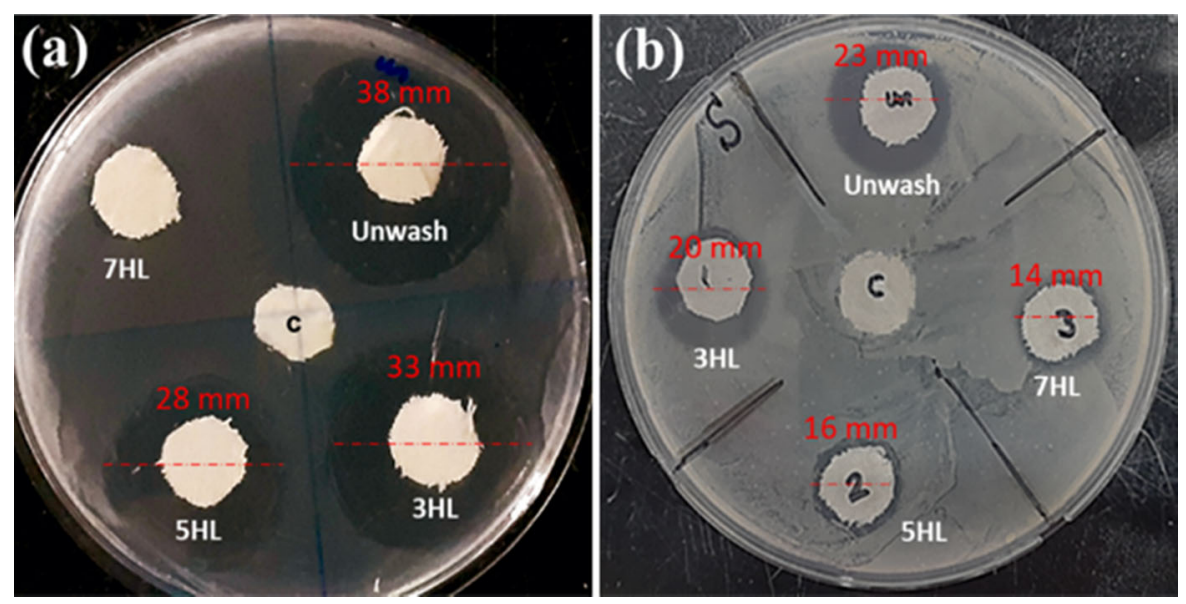

Fig. 7 Antimicrobial performance of as treated sample with wash durability a E. coli b S. aureus 
(a)

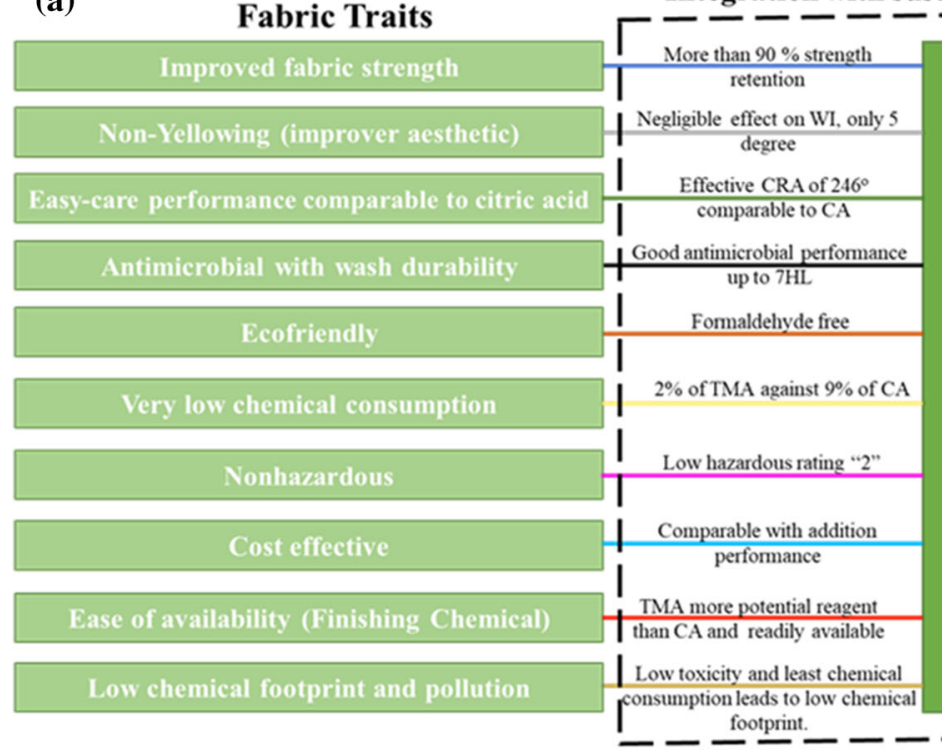

Integration with sustainability

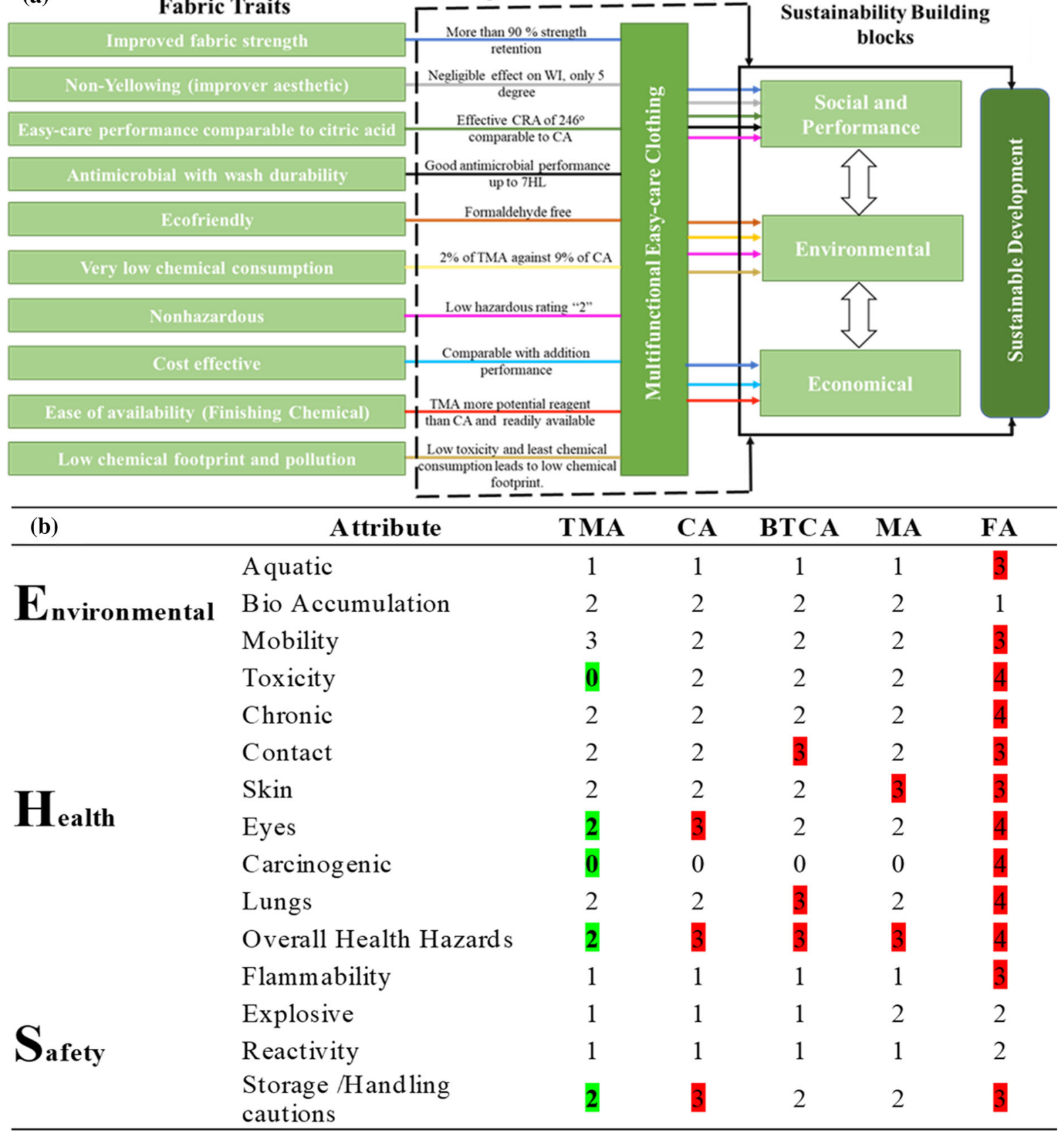

* Based of material safety datasheets and Santa-Cruz biotechnology database. Legends: TMA = Trimesic Acid; CA = Citric Acid; BTCA = 1,2,3,4-Butanetetracarboxylic acid; $M A=$ Maleic Acid; FA = Formaldehyde. Numerical rating based on 0-4 scale: $(0=$ No hazard; 4 = Very high).

Fig. 8 Sustainability study a Sustainability mapping of development with fabric functional traits. b EHS Mapping of the TMA in comparison to different easy-care. finishes

and MA. (Fig. S1, S5). Further, the superiority of TMA-based easy-care finish is also coupled with low chemical consumption of only $2 \%$ (Table 1) for required performance which made it the first choice for adaptation as a green easy-care finish. 


\section{Conclusion}

In this research, cotton fabric was crosslinked with TMA in presence of SHP and copper nanoparticles to impart multifunctional easy-care properties in clothing. The results present successful utilization of trimesic acid as an effective crosslinker to impart easy-care performance without any deterioration of fabric color aesthetic (whiteness) and strength. The crease recovery angle of $248^{\circ}$ was achieved with only $2 \%$ of trimesic acid concentration. Relatively low fabric stiffness and bending length of as-prepared sample validate the better comfort presentation. EDX mapping revealed the uniform distribution of nanoparticles throughout the fabric surface while the XRD spectrum confirms the metallic CuNPs without any oxidation. Further, the detailed EHS mapping represents the superiority of TMA over conventional crosslinkers at a glance while integrations of fabric traits with basic sustainability building blocks pave the path for rapid industrial adoption through rigorous interlinking. With relatively better comfort, substantial durability, and broad-spectrum antimicrobial performance, such a finish can be a promising solution for multifunctional sustainable clothing needs. Future investigation to improve the antimicrobial performance can extend the utilization spectrum in medical textiles.

Funding This work was supported by the Korea Basic Science Institute (KBSI) National Research Facilities \& Equipment Center (NFEC) grant funded by the Korea government (Ministry of Education) (No. 2019R1A6C1010031). This work was partly supported by the GRRC program of Gyeonggi province [GRRC Sungkyunkwan 2017-B03, Development of chemical sensor based on metal oxide materials.

\section{Declarations}

Conflict of interest The authors declare that they have no conflict of interest.

\section{References}

Abdel-Salam OME, Youness ER, Mohammed NA, Morsy SMY, Omara EA, Sleem AA (2014) Citric acid effects on brain and liver oxidative stress in lipopolysaccharidetreated mice. J Med Food 17:588-598. https://doi.org/10. 1089/jmf.2013.0065
Ahmed M, Sukumar N, Gideon RK (2021) Crease resistance finishing optimization of citric acid and fibroin solution for cotton fabrics. J Nat Fibers 18:297-307. https://doi.org/10. 1080/15440478.2019.1623740

Arafa Badr A (2018) Anti-microbial and durability characteristics of socks made of cotton and regenerated cellulosic fibers. Alexandria Eng J 57:3367-3373. https://doi.org/10. 1016/j.aej.2017.11.015

Berradi M, Hsissou R, Khudhair M, Assouag M, Cherkaoui O, El Bachiri A, El Harfi A (2019) Textile finishing dyes and their impact on aquatic environs. Heliyon 5. https://doi.org/ 10.1016/j.heliyon.2019.e02711

Bhaduri R, Bagchi S (2019) Demand aware voltage control of hybrid renewable energy tied uneven multi-level smart inverter. Trans Electr Electron Mater 20:257-268. https:// doi.org/10.1007/s42341-018-00095-2

Chen Q, Tang KPM, Ma P, Jiang G, Xu C (2017) Thermophysiological comfort properties of polyester weft-knitted fabrics for sports T-shirt. J Text Inst 108:1421-1429. https://doi.org/10.1080/00405000.2016.1255122

Deng D, Jin Y, Cheng Y, Qi T, Xiao F (2013) Copper nanoparticles: aqueous phase synthesis and conductive films fabrication at low sintering temperature. ACS Appl Mater Interfaces 5:3839-3846. https://doi.org/10.1021/ am400480k

Doh SJ, Lee JY, Lim DY, Im JN (2013) Manufacturing and analyses of wet-laid nonwoven consisting of carboxymethyl cellulose fibers. Fibers Polym 14:2176-2184. https://doi.org/10.1007/s12221-013-2176-y

Global Antimicrobial Textile Markets to 2025: Massive use of antimicrobial textiles in hospitals.https://www. globenewswire.com/newsrelease/2020/09/11/2092293/0/ en/Global-Antimicrobial-Textile-Markets-to-2025Massive-Use-of-Antimicrobial-Textiles-in-Hospitals. html. Accessed February 2021.

Guesmi A, Taha K, Houas A, Houas A, Hamadi NB, Hellal K, Substances N (2019) Preparation and deposition of copper nanoparticles on cellulose and their antibacterial propriety. J Optoelectron Biomed Mater 11:1-8

Hameed S, Hussain MA, Masood R, Haseeb MT (2016) Crosslinking of cotton fabric using maleic anhydride and sodium hypophosphite. Cellul Chem Technol 50:321-328

Ibrahim NA, Amr A, Eid BM (2020) Multipurpose treatment of cellulose-containing fabrics to impart durable antibacterial and repellent properties. Fibers Polym 21:513-521. https:// doi.org/10.1007/s12221-020-9221-4

Ibrahim NA, Emam EAM, Eid BM, Tawfik TM (2018) An ecofriendly multifunctional nano-finishing of cellulose/wool blends. Fibers Polym 19:797-804. https://doi.org/10.1007/ s12221-018-7922-8

Karim N, Afroj S, Lloyd K, Oaten LC, Andreeva DV, Carr C, Novoselov KS (2020) Sustainable personal protective clothing for healthcare applications: a review. ACS Nano 14:12313-12340. https://doi.org/10.1021/acsnano. $0 \mathrm{c} 05537$

Kolotuchin SV, Fenlon EE, Wilson SR, Loweth CJ, Zimmerman SC (1996) Self-Assembly of 1,3,5-benzenetricarboxylic acids(trimesic acids) and several analogues in the solid state. Angew Chemie Int Ed English 34:2654-2657. https://doi.org/10.1002/anie.199526541 
Kumar M, Jeong DI, Yoon DH (2020) Copper nickel alloy nanorods textured nanoparticles for oxygen evolution reaction. Electrochim Acta 333:135545. https://doi.org/10. 1016/j.electacta.2019.135545

Lange LE, Obendorf SK (2015) Functionalization of cotton fiber by partial etherification and self-assembly of polyoxometalate encapsulated in $\mathrm{Cu}_{3}(\mathrm{BTC})_{2}$ metal-organic framework. ACS Appl Mater Interfaces 7:3974-3980. https://doi.org/10.1021/am506510q

Lee IS, Shin DM, Chung YK (2003) Self-assembly of organometallic-organic hybrid supramolecular arrays from ferrocenyl dipyridines and aromatic carboxylic acids. Cryst Growth Des 3:521-529. https://doi.org/10.1021/ cg0340695

Li X, Pillai SC, Wei L, Liu Z, Huang L, Huang Q, Wang H (2020) Facile synthesis of polyoxometalate-modified metal organic frameworks for eliminating tetrabromobisphenolA from water. J Hazard Mater 399:122946. https://doi.org/ 10.1016/j.jhazmat.2020.122946

Liang T, Yan K, Zhao T, Ji B (2020) Synthesis of a lowmolecular-weight copolymer by maleic acid and acrylic acid and its application for the functional modification of cellulose. Cellulose 27:5665-5675. https://doi.org/10. 1007/s10570-020-03201-x

Lindahl E (2019) The Outdoor Apparel Industry: Measuring the premium for sustainability with a hedonic pricing model. Scripps Senior Theses. 1322. https://scholarship. claremont.edu/scripps_theses/1322/

Liu J, Wang B, Xu X, Chen J, Chen L, Yang Y (2016) Green finishing of cotton fabrics using a xylitol-extended citric acid cross-linking system on a pilot scale. ACS Sustain Chem Eng 4:1131-1138. https://doi.org/10.1021/ acssuschemeng.5b01213

Luo X, Shao D, Wang X, Xu C, Gao W (2020) Whitening citric acid treated cotton fabrics by a TBCC-activated peroxide post-bleaching. Cellulose 27:5367-5376. https://doi.org/ 10.1007/s10570-020-03111-y

Manasoglu G, Kanik M, Yildirim K (2019) Effect of fixation conditions on yellowing behavior of cellulose powdercoated fabrics. J Eng Fibers Fabr 14:1-14. https://doi.org/ $10.1177 / 1558925019829049$

Mohsin M, Carr CM, Rigout M (2013) Development of zero formaldehyde easy care finishing system by using nano titanium dioxide with citric acid and its impact on physical properties. Fibers Polym 14:1440-1444. https://doi.org/10. 1007/s12221-013-1440-5

Mohsin M, Sarwar N, Ahmad S, Rasheed A, Ahmad F, Afzal A, Zafar S (2016) Maleic acid crosslinking of C-6 fluorocarbon as oil and water repellent finish on cellulosic fabrics. J Clean Prod. https://doi.org/10.1016/j.jclepro.2015.10. 045

Nimkar U (2018) Sustainable chemistry: a solution to the textile industry in a developing world. Curr Opin Green Sustain Chem 9:13-17. https://doi.org/10.1016/j.cogsc.2017.11. 002

Patil NV, Netravali AN (2020) Multifunctional sucrose acid as a 'green' crosslinker for wrinkle-free cotton fabrics. Cellulose 27:5407-5420. https://doi.org/10.1007/s10570-02003130-9

Polimbetova GS, Aleshkova MM, Bugubaeva GO, Ibraimova ZU, Borangazieva AK (2004) Oxidative alkoxylation of hypophosphite in coordination sphere of iron(III). Koord Khimiya 30:436-442

Qi H, Zhao C, Qing F, Yan K, Sun G (2016) Antiwrinkle finishing of cotton fabrics with 5-(carbonyloxy succinic)benzene-1,2,4-tricarboxylic acid: comparison with other acids. Ind Eng Chem Res 55:11850-11856. https://doi.org/ 10.1021/acs.iecr.6b03287

Sarwar N, Ashraf M, Mohsin M, Rehman A, Younus A, Javid A, Riaz S (2019) Multifunctional formaldehyde free finishing of cotton by using metal oxide nanoparticles and ecofriendly cross-linkers. Fibers Polym. https://doi.org/10. 1007/s12221-019-9170-y

Sarwar N, Choi SH, Dastgeer G, Humayoun UB, Kumar M, Nawaz A, Yoon DH (2021) Synthesis of citrate-capped copper nanoparticles: A low temperature sintering approach for the fabrication of oxidation stable flexible conductive film. Appl Surf Sci 542:148609. https://doi.org/ 10.1016/j.apsusc.2020.148609

Sarwar N, Bin HU, Khan AA, Kumar M, Nawaz A, Yoo JH (2020) Engineering of sustainable clothing with improved comfort and thermal properties-A step towards reducing chemical footprint. J Clean Prod 261:121189. https://doi. org/10.1016/j.jclepro.2020.121189

Schramm C, Amann A (2019) Formaldehyde-free, crease-resistant functionalization of cellulosic material modified by a hydrolyzed dicarboxylic acid based alkoxysilane/melamine finishing system. Cellulose 26:4641-4654. https:// doi.org/10.1007/s10570-019-02391-3

Shams S, Ahmad W, Memon AH, Shams S, Wei Y, Yuan Q, Liang H (2020) Cu/H 3 BTC MOF as a potential antibacterial therapeutic agent against Staphylococcus aureus and Escherichia coli. New J Chem 44:17671-17678. https:// doi.org/10.1039/D0NJ04120C

Suman R, Javaid M, Haleem A, Vaishya R, Bahl S, Nandan D (2020) Sustainability of coronavirus on different surfaces. J Clin Exp Hepatol. https://doi.org/10.1016/j.jceh.2020.04. 020

Tahvildar A, Ezazshahabi N, Mousazadegan F (2019) Appearance and comfort properties considering yarn-spinning system and weave structure in worsted woven fabrics. J Eng Fiber Fabr. https://doi.org/10.1177/ 1558925019845978

Tausif M, Jabbar A, Naeem MS, Basit A, Ahmad F, Cassidy T (2018) Cotton in the new millennium: advances, economics, perceptions and problems. Text Prog 50:1-66. https://doi.org/10.1080/00405167.2018.1528095

TBRC- The Business Research Company, 2020. Globe News Wire: Sustainable fashion market analysis shows the market progress in attempt to decrease pollution in the global ethical fashion market 2020 https://www. globenewswire.com/news-release/2020/10/28/2116073/0/ en/Sustainable-Fashion-Market-Analysis-Shows-TheMarket-Progress-In-Attempt-To-Decrease-Pollution-InThe-Global-Ethicalfashion-Market-2020.html. Accessed March 2021.

Van-den-Broek J, Klein CD, Pratsinis SE, Güntner AT (2020) Selective formaldehyde detection at ppb in indoor air with a portable sensor. J Hazard Mater 399:123052. https://doi. org/10.1016/j.jhazmat.2020.123052

Wan C, Zhang G, Zhang F (2020) A novel guanidine ammonium phosphate for preparation of a reactive durable flame 
retardant for cotton fabric. Cellulose 27:3469-3483. https://doi.org/10.1007/s10570-020-03003-1

Woźniak-Budych MJ, Przysiecka L, Langer K, peplinska B, Jarek M, wiesner M, Nowaczyk G, Jurga S, (2017) Green synthesis of rifampicin-loaded copper nanoparticles with enhanced antimicrobial activity. J Mater Sci Mater Med 28:42. https://doi.org/10.1007/s10856-017-5857-z

Yokoyama S, Suzuki I, Motomiya K, Takahashi H, Tohji K (2018) Aqueous electrophoretic deposition of citric-acidstabilized copper nanoparticles. Colloids Surfaces A
Physicochem Eng Asp 545:93-100. https://doi.org/10. 1016/j.colsurfa.2018.02.056

Yan L, Li S, Song X (2017) Preparation of paper strengthening agent by esterification of cellulosic fines. Bioresour 12:469-477

Publisher's Note Springer Nature remains neutral with regard to jurisdictional claims in published maps and institutional affiliations. 